Published in final edited form as:

Cancer Epidemiol Biomarkers Prev. 2013 September ; 22(9): 1600-1611. doi:

10.1158/1055-9965.EPI-13-0350.

\title{
Tobacco Smoke Exposure and the Risk of Childhood Acute Lymphoblastic and Myeloid Leukemias by Cytogenetic Subtype
}

\author{
Catherine Metayer ${ }^{1}$, Luoping Zhang ${ }^{1}$, Joseph L. Wiemels ${ }^{2}$, Karen Bartley ${ }^{1}$, Joshua \\ Schiffman ${ }^{3}$, Xiaomei Ma ${ }^{4}$, Melinda C. Aldrich ${ }^{5}$, Jeffrey S. Chang ${ }^{6}$, Steve Selvin ${ }^{1}$, Cecilia H. \\ $\mathrm{Fu}^{7}$, Jonathan Ducore ${ }^{8}$, Martyn T. Smith ${ }^{1}$, and Patricia A. Buffler ${ }^{1}$ \\ ${ }^{1}$ School of Public Health, University of California, Berkeley, USA \\ ${ }^{2}$ Department of Epidemiology and Biostatistics, University of California San Francisco, USA \\ ${ }^{3}$ Department of Pediatrics and Center for Children's Cancer Research, University of Utah, USA \\ ${ }^{4}$ School of Public Health, Yale University, USA \\ ${ }^{5}$ Department of Thoracic Surgery and Division of Epidemiology, Vanderbilt University Medical \\ Center, Vanderbilt University, USA \\ ${ }^{6}$ National Institute of Cancer Research, National Health Research Institutes, Tainan, Taiwan \\ ${ }^{7}$ Division of Hematology/Oncology, Children's Hospital Los Angeles, USA \\ ${ }^{8}$ University of California, Davis, School of Medicine, USA
}

\section{Abstract}

Background-Tobacco smoke contains carcinogens known to damage somatic and germ cells. We investigated the effect tobacco smoke on the risk of childhood acute lymphoblastic leukemia (ALL) and myeloid leukemia (AML), especially subtypes of pre-natal origin like ALL with translocation $\mathrm{t}(12 ; 21)$ or high-hyperdiploidy (51-67 chromosomes).

\begin{abstract}
Methods-We collected information on exposures to tobacco smoking before conception, during pregnancy, and after birth in 767 ALL cases, 135 AML cases, and 1,139 controls (1996-2008). Among cases, chromosome translocations, deletions, or aneuploidy were identified by conventional karyotype and fluorescence in-situ hybridization.
\end{abstract}

\begin{abstract}
Results-Multivariable regression analyses for ALL and AML overall showed no definite evidence of associations with self-reported (yes/no) parental prenatal active smoking and child's passive smoking. However, children with history of paternal prenatal smoking combined with postnatal passive smoking had a 1.5-fold increased risk of ALL (95\% CI: 1.01-2.23), compared to those without smoking history (ORs for pre- or postnatal smoking only were close to one). This joint effect was seen for B-cell precursor ALL with $\mathrm{t}(12 ; 21)(\mathrm{OR}=2.08$; 95\% CI: 1.04-4.16), but not high hyperdiploid B-cell ALL. Similarly, child's passive smoking was associated with an elevated risk of AML with chromosome structural changes (OR=2.76; 95\% CI: 1.01-7.58), but not aneuploidy.
\end{abstract}

Conclusions-our data suggest that exposure to tobacco smoking before were associated with increased risks of childhood ALL and AML; and risks varied by timing of exposure (before and/or after birth) and cytogenetic subtype, based on imprecise estimates.

Corresponding author: Catherine Metayer, School of Public Health, University of California, 1995 University Avenue, Suite 460, Berkeley, CA 94704-7392, USA. Telephone: 510-643-1156; Fax: 510-642-9319; cmetayer@ berkeley.edu.

Conflict of Interest: None 
Impact—Parents should limit exposures to tobacco smoke before and after the child's birth.

\section{Keywords}

Childhood leukemia; tobacco smoking; cytogenetics

\section{INTRODUCTION}

The predominant phenotype of childhood acute lymphoblastic leukemia (ALL) is B-cell precursor ALL. It occurs primarily in young children two to five years of age, while the incidence of the less common T-cell phenotype increases with age (1). B-cell precursor ALL tends to have numerical and structural chromosomal abnormalities such as highhyperdiploidy (defined by the presence of 51-68 chromosomes, referred to as 51+) and translocation $\mathrm{t}(12 ; 21) / E T V 6-R U N X 1$ (also referred to as the TEL-AML1 gene fusion, a molecular cytogenetic abnormality not detectable in conventional cytogenetics), which represent the most common cytogenetic subtypes of B-cell precursor ALL (2). Acute myeloid leukemia (AML) is rare in children, and occurs uniformly across all ages. Childhood AML is often characterized by recurrent chromosomal abnormalities such as $M L L$ fusions located at chromosome 11q23, $\mathrm{t}(8 ; 21), \mathrm{t}(15 ; 17)$, and inv(16) (2).

Genetic mutations leading to leukemic clones take place either during fetal development (e.g., (t12;21)/ETV6-RUNX1), after birth (e.g., $\mathrm{t}(1 ; 19) / E 2 A-P B X 1)$, or possibly during both periods (e.g., $M L L$ fusion) (3). Although molecular markers are used for diagnostic and prognostic purposes, little is known regarding the underlying mechanisms leading to childhood ALL and AML with specific chromosome abnormalities. The distinctive natural history of ALL and AML subtypes may provide clues in identifying periods of susceptibility to certain leukemogenic agents.

Mainstream tobacco smoke (exhaled by the smoker) and sidestream smoke (emitted from a burning tobacco product) contain a mixture of human carcinogens, such as benzene, formaldehyde, 1,3 butadiene, polycyclic aromatic hydrocarbons, and polonium $(4,5)$. Benzene is known to damage cells of myeloid lineage and pluripotent hematopoietic stem cells (6-8), thus potentially playing a role in the development of both childhood AML and ALL. Understanding the effect of tobacco smoke on the risk of childhood leukemia is complex because exposure to tobacco-specific chemicals may affect either somatic or germ cells during critical periods of a child's development (preconception, pregnancy, after birth). While epidemiologic studies conducted worldwide have generally reported no association between maternal smoking during pregnancy and the risk of ALL and AML in the offspring (9), evidence is accumulating in favor of an association between paternal active tobacco smoking before conception and childhood ALL, suggesting a role for germline mutations in disease development $(10,11)$. Data on the relation of tobacco smoking to the risk of specific immunophenotypes $(11-13)$ or cytogenetic subtypes $(11,14)$ of childhood leukemia, however, are sparse.

The current analysis is an expansion of a previous report (15) to assess whether various phenotypic and molecular subtypes of childhood leukemia have distinct associations with child's and parents' exposure to passive (involuntary) and active (voluntary) smoking.

\section{MATERIALS AND METHODS}

\section{Study Population}

The Northern California Childhood Leukemia Study (NCCLS) is a case-control study conducted in 17 counties in Northern California in Phase 1 (1995-1999) and an additional 
18 counties in Central California (35 counties total) in Phase 2 (2000-2008). Cases were identified within 72 hours after diagnosis at seven (Phase 1) or nine (Phase 2) hospitals, and were eligible for participation if they were younger than 15 years of age at diagnosis, had an English or Spanish speaking parent or guardian, lived in one of the 35 counties that comprised the population base at the time of diagnosis, and had never been previously diagnosed with cancer. Comparison of case ascertainment in the 35-county study area to the California Cancer Registry (1997-2003) showed that the NCCLS ascertained 96\% of children diagnosed with leukemia in the Phase 1 participating hospitals and $93 \%$ in the Phase 2 hospitals. When considering both participating and non-participating hospitals within the 35 study counties, $76 \%$ of all diagnosed cases were ascertained in the NCCLS. Eighty six percent of cases determined to be eligible consented to participate.

Eligibility criteria for controls were similar as those for cases. Controls were randomly selected using birth certificates obtained through the California Office of Vital Records, and one or two controls were matched to each case on child's date of birth, sex, Hispanic ethnicity (defined as either one or both parents being Hispanic, as indicated on the birth certificate record), and maternal race (as indicated on the birth certificate record). Out of all potential controls searched, $12 \%$ could not be located, $20 \%$ refused to participate, and $68 \%$ were successfully contacted and considered eligible. Among those contacted and eligible, $86 \%$ agreed to participate. The overall control participation rate was estimated to be 59\%, where the numerator was defined as the number of confirmed eligible controls (68\% of controls contacted) and those presumed to be eligible controls (68\% of controls not located or refusals), and the denominator was defined as all potential controls searched (16). We determined that participating controls were representative of the source population with respect to reproductive and demographic characteristics (17). The study was approved by the University of California Committee for the Protection of Human Subjects, the California Health and Human Services Agency Committee for the Protection of Human Subjects, and the institutional review boards of all participating hospitals. Written informed consent was obtained from the parents of all participating subjects.

\section{Data Collection}

Interviews-During Phase 1, a self-administered questionnaire was used to collect tobacco smoking histories, followed by a home-based, in-person interview administered by trained personnel to obtain additional information. During Phase 2, all information was collected through home-based, in-person interviews. Information on tobacco was collected separately for each parent: paternal smoking was obtained from the mother in Phase 1, and from the father $(69 \%)$, or mother when the father was not available $(31 \%)$ in Phase 2. Calendar aids were provided to enhance recall of time-specific exposures. The median time between date of enrollment and interview was 4 months for cases and 14 months for controls. For mothers and fathers, we collected information on active smoking during lifetime (defined as smoking at least 100 cigarettes, pipes or cigars), three months before conception, and pregnancy, as well as passive smoking at home or in the workplace before or during pregnancy. For children, passive smoking at home was determined by the presence of a person (i.e., mother, father or other person) who smoked at least once a week or more for at least 3 months from birth to the diagnosis/reference date or third birthday, whatever occurred first. In Phase 2, similar information on passive smoking in cars and public places was collected for the child and parents (before or during the mother's pregnancy). The number of cigarettes, pipes, and cigar smoked was collected for paternal smoking 3 months before the pregnancy, as well as maternal smoking before, during, and after the pregnancy.

Medical Record Abstraction-Clinical and laboratory data relevant to immunophenotypic and cytogenetic classification were abstracted from case children's 
medical records, and reviewed for accuracy by a consulting clinical oncologist (JS). Immunophenotype was determined for ALL cases (754 B-cell ALL and 77 T-cell ALL) according to the WHO classification using flow cytometry profiles provided in the pathology report. Cytogenetic classification was determined in pretreated bone marrow specimens at the time of diagnosis using karyotypes ascertained from conventional Gbanding and occasional fluorescence in situ hybridization (FISH).

Additional FISH Analyses-Childhood ALL cases were selected for FISH screening at the University of California, Berkeley laboratory (LZ, MS) if the medical records showed a normal cytogenetic report at diagnosis, failed to provide any data, or had no observed highhyperdiploidy (51+) and/or a common translocation. Of the leukemia cases that met these criteria, only those with available pre-treatment bone marrow aspirate smears had FISH analysis. Specifically, FISH assays were designed to detect both $\mathrm{t}(12 ; 21) / E T V 6-R U N X 1$ and high-hyperdiploidy simultaneously among B-lineage ALL cases ( $>1$ year of age), using probes for chromosome 12p13, chromosome 21q22, and the centromere of chromosome $\mathrm{X}$ (Manufacturer: Vysis, Downers Grove, IL). Additional probes for chromosomes 6, 10, and 18 were applied to cases ambiguous for hyperdiploidy.

Cytogenetic Classification-Diagnostic karyotype for each patient was classified according to clonal genetic aberrations using the International System for Human Cytogenetic Nomenclature 1995 criteria (18). Details on classification of cytogenetic abnormalities by FISH have been described previously (19). Cases having chromosome gains or structural abnormalities required two or more metaphases for designation of clonality, whereas loss of chromosomes necessitated a minimum of three metaphases. Patients having translocations, inversions, deletions, or insertions involving the 11q23/MLL chromosome region were classified as having 11q23/MLL rearrangements. Patients with diploid karyotypes required a minimum of 20 banded metaphases. Classification of ploidy level was made according to the simplest clone. Conventional cytogenetics was used to assign ploidy status, unless the patient had available FISH data and a normal karyotype (or no available sample), whereby FISH was used to assign ploidy. Among the ALL cases with adequate karyotypes, G-banding assigned ploidy to $48.2 \%$ of cases and FISH (done by either a collaborating hospital or University of California, Berkeley) assigned ploidy for the remaining $51.8 \%$ of cases. Classifications were conducted by two individuals (MCA, KB); ambiguous cases ( 9\%) were separately reviewed by an independent reviewer (XM) and inconsistencies were resolved after discussion.

Karyotpe and FISH data were available for 777 ALL and 138 AML. The remaining 62 ALL cases and 6 AML cases had inadequate information or samples and were excluded from analyses stratified by cytogenetic subtype. Table 1 lists the frequency distribution of common cytogenetic types for B-cell precursor ALL and AML reported in the CCLS from 1995 to 2008.

\section{Statistical Analysis}

Because the information on paternal preconception smoking was collected twelve months after the study began, the present analysis includes children enrolled in 1996 and after: 767 ALL cases (689 B-cell ALLs and 70 T-cell ALLs), 135 AML cases, and 1,139 healthy controls (of these, 975 controls were matched to ALL cases and 164 controls matched to AML cases). Analyses were conducted for ALL and AML, and by immunophenotype (for ALL) and cytogenetic subtype. Odds ratios (ORs) and approximate $95 \%$ confidence intervals (CIs) were calculated from unconditional logistic regression models adjusted for child's age at diagnosis, gender, Hispanic ethnicity and maternal race (i.e., Black, White, and Other), and household income. Parental education, parental age at child's birth, child's birth 
weight, home use of paints and solvents, and paternal exposures to organic solvents at work were not included in the final models because they did not change the OR between tobacco exposure and childhood leukemia.

Parental active smoking was highly correlated before and during pregnancy (66\% of mothers and $97 \%$ for fathers smoked both before and during pregnancy). Therefore, we present ORs for maternal and paternal smoking during the prenatal period as a whole. For leukemia subtypes with five or more observations per cell, we assessed the joint effect of exposure to tobacco during the prenatal and postnatal periods, using likelihood ratio tests. To assess homogeneity between leukemia subtypes, we computed chi-square tests based on the Woolf's method (p-value > 0.05 indicates homogeneity). Numbers of cigarettes smoked per day were modeled as counts, and there was no evidence of a departure from linearity.

\section{RESULTS}

Case and control participants were similar with respect to matching characteristics, but differed by household income and maternal education, both of which were higher among controls (Table 2). Household income and parental education was slightly correlated with maternal active smoking (r: 0.01-0.15) or passive smoking (r range: 0.08-0.16) and moderately correlated with paternal active smoking (r: $0.11-0.21)$ and passive smoking (r: $0.15-0.25)$.

The case-control distribution of tobacco smoke exposures and the corresponding ORs and 95\% CIs are presented for ALL overall and immunophenotypes (Tables 3 and 4), cytogenetic subtypes of B-cell precursor ALL (Table 5), and AML overall and cytogenetic subtypes (Table 6). In multivariable models for ALL (Table 3), most ORs for exposure to tobacco smoking at various times were equal or close to one, with possibly the exception of non-statistically significant increased risks of T-cell precursor ALL with prenatal maternal smoking (OR=1.69; 95\% CI: 0.64-4.46), and B-cell precursor ALL with passive smoking at home (OR=1.30; 95\% CI: 0.90-1.88). The model assessing a possible joint effect of paternal prenatal smoking and child's post-natal passive smoking showed that exposure during both periods, compared to none, was associated with an increased risk of ALL overall and B-cell precursor ALL (OR=1.50; 95\% CI: 1.01-2.23 and OR=1.60; 95\% CI: $1.07-2.04$, respectively); however, no increased risks were observed with exposure solely to prenatal paternal smoking or child's passive smoking (p-values for interaction $₫ 8.05$; Table 3). No joint effect of pre-natal maternal smoking and child's passive smoking was reported for childhood ALL. The ORs for every increase in 5 cigarettes smoked per day was 1.06 (95\% CI: 0.98-1.14) for preconception paternal smoking.

Among non-smoking parents, non-statistically significant increased risks of childhood ALL $(\mathrm{OR}=1.50,95 \%$ CI: 0.84-2.69) and B-cell precursor ALL (OR=1.66, 95\% CI: 0.92-3.00) were observed when fathers were exposed to tobacco smoke in cars during the preconception period (Table 4); mothers' exposure to passive smoking in cars was rare. Children exposed to tobacco smoke in cars but not at home also experienced a 1.5-fold nonstatistically significant increased risk of B-cell precursor ALL (95\% CI: 0.71-3.54; 11 cases and 16 controls). There were no associations between childhood ALL and a father's or mother's passive smoking at home, work, or in public areas.

Exposure to tobacco smoke before and after birth was not associated with an elevated risk of childhood B-ALL with high hyperdiploidy, in contrast to other cytogenetic subtypes (Table 5). Paternal prenatal smoking combined with child's passive smoking was associated with an increased risk of childhood B-cell precursor with $\mathrm{t}(12 ; 21)(\mathrm{OR}=2.08,95 \% \mathrm{CI}: 1.04-4.16)$, but not for B-cell precursor ALL with high-hyperdiploidy (OR=1.01, 95\% CI: 0.54-1.87; p- 
value for homogeneity $=0.04$ ) (Table 5). Maternal prenatal smoking was associated with no or reduced risks of all B-cell ALL cytogenetic subtypes; specifically, we observed a deficit of B-cell ALL with chromosome translocations other than $\mathrm{t}(12: 21)(\mathrm{OR}=0.24,95 \%$ CI: $0.06-0.89)$.

Non-statistically significant increased risks of childhood AML were observed with prenatal maternal and paternal active smoking, and child's passive smoking at home (Table 6). The latter association was of a larger magnitude for AML with recurrent chromosome aberrations known to confer a favorable prognosis ( $\mathrm{OR}=2.76,95 \%$ CI: $1.01-7.58 ; 15$ exposed cases). No associations were found between tobacco smoke and AML with aneuploidy. Lastly, childhood leukemias (ALL or AML) with $M L L$ fusion (n=34) were not associated with any exposure to tobacco smoke (data not shown).

\section{DISCUSSION}

Subtypes of childhood ALL exhibit specific molecular characteristics known to be important in risk stratification and treatment specification at diagnosis. These molecular characteristics may have distinctive mechanistic origins and could be useful stratification criteria for epidemiologic analysis as well. Indeed, hyperdiploidy results from a presumed "chaotic" mitosis, which contrasts sharply with the mechanism of translocations, which involve double stranded DNA breaks and DNA repair (3). We previously reported an association between home use of paints and the risk of B-cell precursor ALL, with marked differences in risk between (t12;21)/ETV6-RUNX1 and hyperdiploid subtypes (20). Similarly, the observed association between home use of petroleum solvents and childhood AML was limited to those with chromosomal structural changes (20).

Time- and subtype-specific analyses in our study suggested that the risk of childhood ALL was associated with a history of paternal prenatal active smoking combined with child's postnatal exposure to passive smoking at home, and that the magnitude of association was the strongest for B-cell precursor ALL harboring $\mathrm{t}(12 ; 21)$. No association was found with high-hyperdiploid ALL, and associations seen with other cytogenetic subtypes did not reach statistical significance. Most individual studies and meta-analyses have reported no association between maternal smoking during pregnancy and childhood ALL $(9,21)$, and small to moderate positive associations between preconception paternal smoking and childhood ALL $(10,11)$. However, evaluations of the risk by main immunophenotype or cytogenetic subtype remain sparse. In a French study, elevated risks following paternal smoking from one year before conception to the time of the interview, were reported for both B-cell precursor ALL ( $\mathrm{n}=545)$, and T-cell ALL ( $\mathrm{n}=67$ ) (13). An Australian study reported an increased risk of ALL overall with paternal smoking during the conception year, and no difference in risk by immunophenotype ( $\mathrm{n}=294$ pre-B-cell ALL; number of T-cell ALL not provided) (11). The lack of association we observed between preconception paternal smoking and childhood T-cell ALL $(n=69)$ is in contrast with these earlier observations. Other childhood leukemia studies have investigated in utero exposures specific to infant leukemia with $M L L$ rearrangements, showing associations with maternal consumption of food that contains topoisomerase II inhibitors during pregnancy $(22,23)$ and transplacental chemical exposures (24), but not maternal smoking (14). We also reported no associations with any sources of tobacco smoking and childhood leukemia with $M L L$ rearrangement. To our knowledge, only the study by Milne et al. (11) has examined the risk of childhood ALL by cytogenetic type in older children. Although limited by small sample sizes, the authors reported no apparent differences in risks associated with paternal smoking for ALL with high hyperdiploidy $(\mathrm{n}=82)$ and those with $\mathrm{t}(12 ; 21)(\mathrm{n}=60)(11)$. 
Results published on a limited subset of children with AML enrolled in the NCCLS ( $\mathrm{n}=46$ ) showed a three-fold increased risk following preconception paternal active smoking, based on unstable risk estimates (15). The current updated analysis reports a non-statistically significant increased risk of AML with paternal prenatal active smoking, as well as child's passive smoking at home (Table 6). With the exception of one study (25), all studies have reported no association between paternal smoking and childhood AML (26). The main limitation of studies of childhood AML is the lack of statistical power due to the rarity of the disease, further complicated by its molecular heterogeneity. Although our observation of differential AML risks by cytogenetic profile is based on imprecise estimates, several caseonly studies of tobacco smoking and the risk of adult AML have also reported a higher risk for AML with any chromosome abnormalities (27), complex karyotype $(28,29)$, or specific aberrations such as $\mathrm{t}(8 ; 21)(27,30),-7 / \mathrm{del}(7 \mathrm{q})(28-30),+8(27,29), \mathrm{t}(8: 21), \mathrm{t}(15 ; 17)$, or $\operatorname{inv}(16)$ (28) (not all associations reached statistical significance).

It is well established that tobacco-related contaminants can damage DNA in human somatic cells, and there is growing evidence that tobacco affects germ cells not only in animals, but in humans (31). Biologic studies $(3,32)$ investigating the origin of leukemic clones in children have also detected molecular lesions in the neonatal blood spots, supporting the hypothesis that an "initiating genetic hit" occurs before birth. Common prenatal lesions include (t12;21)/ETV6-RUNX1 and hyperdiploidy in childhood ALL and $\mathrm{t}(8 ; 21) / A M L 1$ $E T O$ in childhood AML, while $\mathrm{t}(1 ; 19) / E 2 A-P B X 1$, the second most frequent translocation in childhood ALL, appears to occur after birth. The translocation $\mathrm{t}(12 ; 21) / E T V 6-R U N X 1$ is present in about $20 \%$ of children with B-cell precursor ALL, yet on a population level is much more prevalent at birth (33), suggesting that a "second genetic hit" after birth is likely to be necessary to cause leukemia. The current data are consistent with our earlier observation (15) showing that the combination of paternal preconception smoking and child's passive smoking distinctly increased the risk of childhood ALL with t(12;21), consistent with the two-step model for childhood leukemia. In this instance, the first genetic hit would occur before conception via genotoxic effects of tobacco smoke on germ cells (the sperm), and the second hit would occur after the child's birth via carcinogenic effects on somatic cells through passive smoking. Because fathers in our study usually smoke before and during pregnancy, we cannot rule out that exposure to tobacco smoke via the mother's passive smoking may also affect the fetus (although this alternative explanation is weakened by the fact that mother's active smoking does not appear to be associated with an increased risk of childhood ALL). Also, information on the total number of cigarettes smoked per day after the child's birth was not available, limiting our ability to assess differences with respect to pre- and/or post-natal exposure to tobacco smoke. We observed a decreased risk of B-cell precursor ALL harboring translocations other than $(\mathrm{t} 12 ; 21)$ following maternal prenatal smoking, however findings for rare cytogenetic subtypes should be interpreted with caution due to small numbers. While epidemiologic data may corroborate current knowledge about the natural history of specific leukemia subtypes, the mechanisms through which chemicals in tobacco smoke cause selected chromosomal break points remain unclear. Subtypespecific associations may result from other means than breaking chromosomes such as protein modification, signal transduction changes, or cell toxicity in which specific subtypes display more sensitivity.

Children may be exposed to second-hand smoke in the presence of a smoker at home, as well as to residues deposited on surfaces (referred to as third-hand smoking) (34). In our study, about $6 \%$ of children were also exposed to smoke while inside a car, and those uniquely exposed to passive smoking in cars (not at home) were at higher risk of B-cell precursor ALL than children exposed at home. Similarly, non-smoking fathers exposed to tobacco smoke in cars (but not at home, workplace, and public areas) were at increased risk of having children with B-cell precursor ALL. Possible mechanisms to explain this 
observation include germ cell damage during the preconception period as described earlier, and/or child's exposure to third-hand smoke via particle tracked into the child's environment. Sidestream and mainstream smoke contain similar mixtures of chemicals, but their concentrations vary depending on the smoke emission rates (35). Measurement studies of fine particulate matter and other markers of tobacco exposure have documented that smoking in a confined space like cars results in exposure to very high levels of tobaccorelated chemicals $(36,37)$.

Our results should be interpreted in the context of the limitations and strength of the study. The NCCLS is the largest epidemiologic study to examine the association between exposure to tobacco smoke and the risk of leukemia harboring common chromosomal abnormalities. We recognize that replication of our observations in other large studies, individual or pooled such as in the Childhood Leukemia International Consortium (CLIC), are needed to provide more precise estimates. Differential recall of tobacco smoking history between case and control families is a valid concern in case-control studies. Although tobacco smoking is a multiple organ site carcinogen, its association with hematologic malignancies is probably not well known to the general public. Also, the fact that we observed both positive and negative findings by leukemia subtype may be an indication that differential recall bias has limited influence on the results. Information on paternal tobacco smoking was collected through the mother or father depending on the phase of the study and availability of the father (see Methods section). A subset of parents of 107 cases and 108 controls from the NCCLS was recruited to assess the agreement between the mother's and father's selfreported information on father's smoking. Using kappa statistics, the overall agreement for father's current smoking, father's lifetime smoking, and father's smoking during the three months prior to mother's pregnancy was substantial based on the scale proposed by Landis and Koch (38), with kappa=0.76 (95\% CI:0.60-0.91); 0.73 (95\% CI:0.63-0.83) and 0.70 (95\% CI:0.56-0.84), respectively. Agreement was higher among parents of cases, with higher education, and non-Hispanic Whites, as well as when the interval between the child's birth and diagnosis for cases (or reference date for controls) was less than 6 years. As the peak incidence of ALL is observed in children 2-5 years old, our findings regarding ALL should not have been substantially affected by who completed the interview (i.e., mother versus father). Also we found no apparent difference in risks between Hispanics and nonHispanic children.

In this analysis, controls have significantly higher household income and maternal education levels than cases, which may reflect a true observation or alternatively result from selection bias. Also, history of paternal and maternal smoking was associated with markers of socioeconomic status. In particular, the combination of prenatal paternal smoking and passive smoking was more frequent in households with low income and father's education, whereas smoking only during one period (before or after the child's birth) was more common in households with higher income and father's education. However, this observation was true for both cases and controls, and may not have substantially biased the results. All models were adjusted for household income, and additional adjustment for other socioeconomic markers such as parental education and age at child's birth did not influence the risk estimates.

The strengths of our study include the ultra-rapid ascertainment of children diagnosed with incident leukemia, the high participation rate (95\%) of cases in the participating hospitals, the centralized review of medical abstracts by a pediatric oncologist to confirm the histology, immunophenotype, and karyotype of all leukemias, and additional FISH analyses performed at a central laboratory to complete cytogenetic characterization on over $90 \%$ of leukemia cases, using pre-treatment bone marrow and blood specimens. We collected 
detailed information on tobacco smoking history, including data on parent's passive smoking in various locations.

Our data suggest that combined exposures to tobacco smoking before the child's birth-including during the preconception period--and after birth are involved in the etiology of childhood ALL, consistent with the two-step model for leukemogenesis. The associations with tobacco smoking varied by cytogenetic subtype of B-cell ALL and possibly AML, although based on imprecise estimates.

\title{
Acknowledgments
}

\begin{abstract}
We thank the families for their participation. We also thank the clinical investigators at the following collaborating hospitals for help in recruiting patients: University of California Davis Medical Center (Dr. Jonathan Ducore), University of California San Francisco (Drs. Mignon Loh and Katherine Matthay), Children's Hospital of Central California (Dr. Vonda Crouse), Lucile Packard Children's Hospital (Dr. Gary Dahl), Children's Hospital Oakland (Dr. James Feusner), Kaiser Permanente Roseville (former Sacramento) (Drs. Kent Jolly and Vincent Kiley), Kaiser Permanente Santa Clara (Drs. Carolyn Russo, Alan Wong and Denah Taggar), Kaiser Permanente San Francisco (Dr. Kenneth Leung) and Kaiser Permanente Oakland (Drs. Daniel Kronish and Stacy Month). Finally, we acknowledge the entire California Childhood Leukemia Study staff and the former UCB Survey Research Center for their effort and dedication.
\end{abstract}

Funding: National Institute of Environmental Health Sciences (Grant numbers R01ES009137 and P42ES004705), USA, and Children with Cancer, United Kingdom. The content is solely the responsibility of the authors and does not necessarily represent the official views of the National Institute of Environmental Health Sciences.

\section{References}

1. Ries, LAG.; SEER Program (National Cancer Institute (U.S.)). Cancer incidence and survival among children and adolescents : United States SEER program 1975-1995. Vol. vi. National Cancer Institute SEER Program; Bethesda, MD: 1999. p. 182

2. Pui, C-H. Childhood leukemias. Vol. xii. Cambridge University Press; Cambridge, UK; New York, NY: 1999. p. 567

3. Greaves MF, Wiemels J. Origins of chromosome translocations in childhood leukaemia. Nature reviews Cancer. 2003; 3(9):639-49. Epub 2003/09/03.

4. Cogliano VJ, Baan R, Straif K, Grosse Y, Lauby-Secretan B, El Ghissassi F, et al. Preventable exposures associated with human cancers. Journal of the National Cancer Institute. 2011; 103(24): 1827-39. Epub 2011/12/14. [PubMed: 22158127]

5. Zaga V, Lygidakis C, Chaouachi K, Gattavecchia E. Polonium and lung cancer. Journal of oncology. 2011; 2011:860103. Epub 2011/07/21. [PubMed: 21772848]

6. International Agency for Research on Cancer. Overall evaluation of carcinogenicity : an updating of IARC monographs. Vol. vol.1 to 42. IARC; Lyon: 1987. p. 440

7. Goldstein BD. Benzene as a cause of lymphoproliferative disorders. Chemico-biological interactions. 2010; 184(1-2):147-50. Epub 2009/12/29. [PubMed: 20035727]

8. Smith MT. Advances in understanding benzene health effects and susceptibility. Annual review of public health. 2010; 31:133-48 2 p following 48. Epub 2010/01/15.

9. Klimentopoulou A, Antonopoulos CN, Papadopoulou C, Kanavidis P, Tourvas AD, Polychronopoulou S, et al. Maternal smoking during pregnancy and risk for childhood leukemia: a nationwide case-control study in Greece and meta-analysis. Pediatric blood \& cancer. 2012; 58(3): 344-51. Epub 2011/10/13. [PubMed: 21990018]

10. Liu R, Zhang L, McHale CM, Hammond SK. Paternal smoking and risk of childhood acute lymphoblastic leukemia: systematic review and meta-analysis. Journal of oncology. 2011; 2011:854584. Epub 2011/07/19. [PubMed: 21765828]

11. Milne E, Greenop KR, Scott RJ, Bailey HD, Attia J, Dalla-Pozza L, et al. Parental prenatal smoking and risk of childhood acute lymphoblastic leukemia. American journal of epidemiology. 2012; 175(1):43-53. Epub 2011/12/07. [PubMed: 22143821] 
12. Brondum J, Shu XO, Steinbuch M, Severson RK, Potter JD, Robison LL. Parental cigarette smoking and the risk of acute leukemia in children. Cancer. 1999; 85(6):1380-8. Epub 1999/04/03. [PubMed: 10189146]

13. Rudant J, Clavel J, Infante-Rivard C. Selection bias in case-control studies on household exposure to pesticides and childhood acute leukemia. Journal of exposure science \& environmental epidemiology. 2010; 20(4):299-309. Epub 2009/12/17. [PubMed: 20010976]

14. Slater ME, Linabery AM, Blair CK, Spector LG, Heerema NA, Robison LL, et al. Maternal prenatal cigarette, alcohol and illicit drug use and risk of infant leukaemia: a report from the Children's Oncology Group. Paediatric and perinatal epidemiology. 2011; 25(6):559-65. Epub 2011/10/11. [PubMed: 21980945]

15. Chang JS, Selvin S, Metayer C, Crouse V, Golembesky A, Buffler PA. Parental smoking and the risk of childhood leukemia. American journal of epidemiology. 2006; 163(12):1091-100. Epub 2006/04/07. [PubMed: 16597704]

16. Bartley K, Metayer C, Selvin S, Ducore J, Buffler P. Diagnostic X-rays and risk of childhood leukaemia. International journal of epidemiology. 2010; 39(6):1628-37. Epub 2010/10/05. [PubMed: 20889538]

17. Ma X, Buffler PA, Layefsky M, Does MB, Reynolds P. Control selection strategies in case-control studies of childhood diseases. American journal of epidemiology. 2004; 159(10):915-21. Epub 2004/05/07. [PubMed: 15128601]

18. Mitelman, F. ISCN (1995): An International System for Human Cytogenetic Nomenclature. Basel (Switzerland): 1995.

19. Aldrich MC, Zhang L, Wiemels JL, Ma X, Loh ML, Metayer C, et al. Cytogenetics of Hispanic and White children with acute lymphoblastic leukemia in California. Cancer epidemiology, biomarkers \& prevention : a publication of the American Association for Cancer Research, cosponsored by the American Society of Preventive Oncology. 2006; 15(3):578-81. Epub 2006/03/16.

20. Scelo G, Metayer C, Zhang L, Wiemels JL, Aldrich MC, Selvin S, et al. Household exposure to paint and petroleum solvents, chromosomal translocations, and the risk of childhood leukemia. Environmental health perspectives. 2009; 117(1):133-9. Epub 2009/01/24. [PubMed: 19165400]

21. Bonaventure A, Goujon-Bellec S, Rudant J, Orsi L, Leverger G, Baruchel A, et al. Maternal smoking during pregnancy, genetic polymorphisms of metabolic enzymes, and childhood acute leukemia: the ESCALE study (SFCE). Cancer causes \& control : CCC. 2012; 23(2):329-45. Epub 2011/12/28. [PubMed: 22200898]

22. Ross JA. Dietary flavonoids and the MLL gene: A pathway to infant leukemia? Proceedings of the National Academy of Sciences of the United States of America. 2000; 97(9):4411-3. Epub 2000/04/26. [PubMed: 10781030]

23. Spector LG, Xie Y, Robison LL, Heerema NA, Hilden JM, Lange B, et al. Maternal diet and infant leukemia: the DNA topoisomerase II inhibitor hypothesis: a report from the children's oncology group. Cancer epidemiology, biomarkers \& prevention : a publication of the American Association for Cancer Research, cosponsored by the American Society of Preventive Oncology. 2005; 14(3): 651-5. Epub 2005/03/16.

24. Alexander FE, Patheal SL, Biondi A, Brandalise S, Cabrera ME, Chan LC, et al. Transplacental chemical exposure and risk of infant leukemia with MLL gene fusion. Cancer research. 2001; 61(6):2542-6. Epub 2001/04/06. [PubMed: 11289128]

25. Sorahan T, Prior P, Lancashire RJ, Faux SP, Hulten MA, Peck IM, et al. Childhood cancer and parental use of tobacco: deaths from 1971 to 1976. British journal of cancer. 1997; 76(11):152531. Epub 1997/01/01. [PubMed: 9400953]

26. Chang JS. Parental smoking and childhood leukemia. Methods Mol Biol. 2009; 472:103-37. Epub 2008/12/25. [PubMed: 19107431]

27. Crane MM, Strom SS, Halabi S, Berman EL, Fueger JJ, Spitz MR, et al. Correlation between selected environmental exposures and karyotype in acute myelocytic leukemia. Cancer epidemiology, biomarkers \& prevention : a publication of the American Association for Cancer Research, cosponsored by the American Society of Preventive Oncology. 1996; 5(8):639-44. Epub 1996/08/01. 
28. Bjork J, Albin M, Mauritzson N, Stromberg U, Johansson B, Hagmar L. Smoking and acute myeloid leukemia: associations with morphology and karyotypic patterns and evaluation of doseresponse relations. Leukemia research. 2001; 25(10):865-72. Epub 2001/09/05. [PubMed: 11532519]

29. Bjork J, Johansson B, Broberg K, Albin M. Smoking as a risk factor for myelodysplastic syndromes and acute myeloid leukemia and its relation to cytogenetic findings: a case-control study. Leukemia research. 2009; 33(6):788-91. Epub 2008/11/21. [PubMed: 19019430]

30. Lebailly P, Willett EV, Moorman AV, Roman E, Cartwright R, Morgan GJ, et al. Genetic polymorphisms in microsomal epoxide hydrolase and susceptibility to adult acute myeloid leukaemia with defined cytogenetic abnormalities. British journal of haematology. 2002; 116(3): 587-94. Epub 2002/02/19. [PubMed: 11849215]

31. DeMarini DM. Genotoxicity of tobacco smoke and tobacco smoke condensate: a review. Mutation research. 2004; 567(2-3):447-74. Epub 2004/12/02. [PubMed: 15572290]

32. Wiemels JL, Leonard BC, Wang Y, Segal MR, Hunger SP, Smith MT, et al. Site-specific translocation and evidence of postnatal origin of the $\mathrm{t}(1 ; 19) \mathrm{E} 2 \mathrm{~A}-\mathrm{PBX} 1$ fusion in childhood acute lymphoblastic leukemia. Proceedings of the National Academy of Sciences of the United States of America. 2002; 99(23):15101-6. Epub 2002/11/05. [PubMed: 12415113]

33. Mori H, Colman SM, Xiao Z, Ford AM, Healy LE, Donaldson C, et al. Chromosome translocations and covert leukemic clones are generated during normal fetal development. Proceedings of the National Academy of Sciences of the United States of America. 2002; 99(12): 8242-7. Epub 2002/06/06. [PubMed: 12048236]

34. Matt GE, Quintana PJ, Destaillats H, Gundel LA, Sleiman M, Singer BC, et al. Thirdhand tobacco smoke: emerging evidence and arguments for a multidisciplinary research agenda. Environmental health perspectives. 2011; 119(9):1218-26. Epub 2011/06/02. [PubMed: 21628107]

35. Pieraccini G, Furlanetto S, Orlandini S, Bartolucci G, Giannini I, Pinzauti S, et al. Identification and determination of mainstream and sidestream smoke components in different brands and types of cigarettes by means of solid-phase microextraction-gas chromatography-mass spectrometry. Journal of chromatography A. 2008; 1180(1-2):138-50. Epub 2008/01/08. [PubMed: 18177880]

36. Muller D, Klingelhofer D, Uibel S, Groneberg DA. Car indoor air pollution - analysis of potential sources. J Occup Med Toxicol. 2011; 6(1):33. Epub 2011/12/20. [PubMed: 22177291]

37. Semple S, Apsley A, Galea KS, Maccalman L, Friel B, Snelgrove V. Secondhand smoke in cars: assessing children's potential exposure during typical journey conditions. Tobacco control. 2012 Epub 2012/01/06.

38. Landis JR, Koch GG. The measurement of observer agreement for categorical data. Biometrics. 1977; 33(1):159-74. Epub 1977/03/01. [PubMed: 843571] 
Table 1

Common cytogenetic subtypes of B-cell precursor acute lymphocytic leukemia (ALL) and acute myeloid leukemia (AML): the Northern California Childhood Leukemia Study, 1995-2008

\begin{tabular}{|c|c|c|c|c|c|}
\hline \multicolumn{3}{|c|}{ B-cell precursor ALL $\left(n=701{ }^{a}\right)$} & \multicolumn{3}{|l|}{$\operatorname{AML}\left(n=138^{b}\right)$} \\
\hline & $\mathbf{N}$ & $(\%)^{c}$ & & $\mathbf{N}$ & $(\%)^{c}$ \\
\hline No apparent abnormality & 73 & $(10.4)$ & No apparent abnormality & 25 & $(18.1)$ \\
\hline Total structural changes & 397 & $(56.6)$ & Total structural changes & 103 & $(74.6)$ \\
\hline Translocation $\mathrm{t}(12 ; 21)$ & 143 & $(20.4)$ & Translocation $\mathrm{t}(8 ; 21)$ & 21 & $(15.2)$ \\
\hline Translocations other than $\mathrm{t}(12 ; 21)$ & 87 & $(12.4)$ & Translocation t $(15 ; 17)$ & 14 & $(10.1)$ \\
\hline $\mathrm{t}(1 ; 19)$ & 23 & $(3.3)$ & Inversion inv(16) & 7 & $(5.1)$ \\
\hline $\mathrm{t}(9 ; 22)$ & 8 & $(1.1)$ & & & \\
\hline 11q23/MLL rearrangement & 22 & $(3.1)$ & 11q23/MLL rearrangement & 17 & $(12.3)$ \\
\hline Any deletion & 75 & $(10.7)$ & Any deletion & 21 & $(15.2)$ \\
\hline $\operatorname{del}(12 p)$ & 36 & $(5.1)$ & $\operatorname{del}(9 q)$ & 5 & (3.6) \\
\hline $\operatorname{del}(6 q)$ & 17 & $(2.4)$ & & & \\
\hline $\operatorname{del}(9 p)$ & 17 & $(2.4)$ & & & \\
\hline Total numerical changes & 413 & $(58.9)$ & Total numerical changes & 55 & $(39.9)$ \\
\hline Trisomy 8 & 52 & $(7.4)$ & Trisomy 8 & 18 & $(13.0)$ \\
\hline Monosomy 7 & 18 & $(2.6)$ & & & \\
\hline \multicolumn{6}{|l|}{ Ploidy level } \\
\hline High hyperdiploidy (51-67 chr.) & 237 & $(33.8)$ & & & \\
\hline Low hyperdiploidy (47-50 chr.) & 112 & $(16.0)$ & Low hyperdiploidy (47-50 chr.) & 31 & $(22.5)$ \\
\hline Hypodiploidy (45 chr.) & 28 & $(4.0)$ & Hypodiploidy (45 chr.) & 9 & $(6.5)$ \\
\hline Pseudodiploid & 183 & $(26.1)$ & Pseudodiploid & 71 & $(51.4)$ \\
\hline \multicolumn{6}{|l|}{ Abbreviation: chr. $=$ chromosome } \\
\hline
\end{tabular}


Table 2

Socio-demographic characteristics of children with leukemia and controls recruited in the Northern California Childhood Leukemia Study, 1996-2008

\begin{tabular}{|c|c|c|c|c|c|c|c|c|}
\hline & \multicolumn{4}{|c|}{ Acute Lymphocytic Leukemia } & \multicolumn{4}{|c|}{ Acute Myeloid Leukemia } \\
\hline & \multicolumn{2}{|c|}{ Cases } & \multicolumn{2}{|c|}{ Controls } & \multicolumn{2}{|c|}{ Cases } & \multicolumn{2}{|c|}{ Controls } \\
\hline & $\mathrm{N}^{a}$ & $(\%)$ & $\mathbf{N}^{a}$ & $(\%)$ & $\mathbf{N}^{b}$ & $(\%)$ & $\mathbf{N}^{b}$ & $(\%)$ \\
\hline & 767 & & 975 & & 135 & & 164 & \\
\hline \multicolumn{9}{|l|}{ Child's sex } \\
\hline Male & 431 & (56) & 560 & $(57)$ & 72 & (53) & 89 & $(54)$ \\
\hline Female & 336 & (44) & 415 & $(43)$ & 63 & (47) & 75 & $(46)$ \\
\hline \multicolumn{9}{|l|}{ Child's age at diagnosis (years) } \\
\hline $0-1$ & 83 & (11) & 105 & (11) & 38 & (30) & 51 & $(31)$ \\
\hline$>1-2$ & 436 & (57) & 561 & $(58)$ & 28 & (19) & 32 & $(20)$ \\
\hline$>2-5$ & 110 & (14) & 144 & (15) & 17 & (13) & 22 & (13) \\
\hline$>5-7$ & 138 & (18) & 165 & (17) & 52 & (38) & 59 & (36) \\
\hline Mean & 5.5 & (SD 3.5) & 5.4 & (SD 3.4) & 6.6 & (SD 4.9) & 6.3 & $(\mathrm{SD} 4.8)$ \\
\hline \multicolumn{9}{|l|}{ Child's race/ethnicity } \\
\hline Hispanic & 362 & (47) & 416 & $(43)$ & 61 & (45) & 69 & $(42)$ \\
\hline Non-Hispanic White & 267 & (35) & 391 & $(40)$ & 50 & (37) & 64 & (39) \\
\hline Non-Hispanic others & 138 & (18) & 168 & (17) & 24 & (18) & 31 & (19) \\
\hline \multicolumn{9}{|l|}{ Household annual income (USD) } \\
\hline$<15,000$ & 119 & (16) & 96 & $(10)$ & 28 & (21) & 13 & (8) \\
\hline $15,000-29,999$ & 136 & (18) & 123 & (13) & 24 & (18) & 25 & $(15)$ \\
\hline $30,000-44,999$ & 120 & (16) & 120 & (12) & 20 & (15) & 17 & $(10)$ \\
\hline $45,000-59,999$ & 110 & (14) & 136 & (14) & 14 & (10) & 26 & (16) \\
\hline $60,000-74,999$ & 56 & (7) & 108 & $(11)$ & 12 & (9) & 14 & (9) \\
\hline$\geq 75,000$ & 226 & (29) & 392 & $(40)$ & 37 & (27) & 69 & $(42)$ \\
\hline \multicolumn{9}{|l|}{ Mother's age at birth (years) } \\
\hline Mean & 28.3 & $(\mathrm{SD} 6.2)$ & 29.2 & (SD 6.1) & 27.8 & (SD 6.6) & 29.7 & $(\mathrm{SD} 5.9)$ \\
\hline \multicolumn{9}{|l|}{ Mother's education } \\
\hline No schooling or elementary school & 91 & (12) & 75 & $(8)$ & 13 & (10) & 16 & $(10)$ \\
\hline High school or similar & 248 & (32) & 269 & $(28)$ & 48 & (36) & 44 & (27) \\
\hline College or similar & 215 & (28) & 302 & $(31)$ & 33 & (24) & 43 & (26) \\
\hline Bachelor's degree or higher & 213 & (28) & 328 & (34) & 41 & (30) & 61 & (37) \\
\hline Unknown & 0 & 0 & 1 & $(0)$ & 0 & 0 & 0 & 0 \\
\hline \multicolumn{9}{|l|}{ Father's age at birth (years) } \\
\hline Mean & 31 & $(\mathrm{SD} 7.0)$ & 31.7 & (SD 7.2) & 30.7 & (SD 7.3) & 32.0 & $(\mathrm{SD} 6.4)$ \\
\hline Father's education & & & & & & 0 & & \\
\hline No schooling or elementary school & 93 & (12) & 102 & $(10)$ & 15 & (11) & 17 & $(10)$ \\
\hline High school or similar & 269 & (35) & 295 & $(30)$ & 56 & (41) & 52 & $(32)$ \\
\hline College or similar & 152 & (20) & 247 & $(25)$ & 19 & (14) & 38 & (23) \\
\hline
\end{tabular}




\begin{tabular}{|c|c|c|c|c|c|c|c|c|}
\hline & \multicolumn{4}{|c|}{ Acute Lymphocytic Leukemia } & \multicolumn{4}{|c|}{ Acute Myeloid Leukemia } \\
\hline & \multicolumn{2}{|c|}{ Cases } & \multicolumn{2}{|c|}{ Controls } & \multicolumn{2}{|c|}{ Cases } & \multicolumn{2}{|c|}{ Controls } \\
\hline & $\mathrm{N}^{a}$ & $(\%)$ & $\mathbf{N}^{a}$ & $(\%)$ & $\mathbf{N}^{b}$ & $(\%)$ & $\mathbf{N}^{b}$ & $(\%)$ \\
\hline & 767 & & 975 & & 135 & & 164 & \\
\hline Bachelor's degree or higher & 230 & $(30)$ & 302 & $(31)$ & 42 & (31) & 54 & (33) \\
\hline Unknown & 23 & (3) & 29 & (3) & 3 & (2) & 3 & (2) \\
\hline
\end{tabular}

Abbreviations: $\mathrm{SD}=$ standard deviation; USD=United States dollars

${ }_{\text {includes }} 113$ cases /146 controls in Phase 1 (1996-1999; 1995 excluded from the analyses ) and 654 cases / 829 controls in Phase 2 (2000-2008).

$b_{\text {includes }} 32$ cases / 37 controls in Phase 1 (1996-1999; 1995 excluded from the analyses ) and 103 cases /127 controls in Phase 2 (2000-2008). 


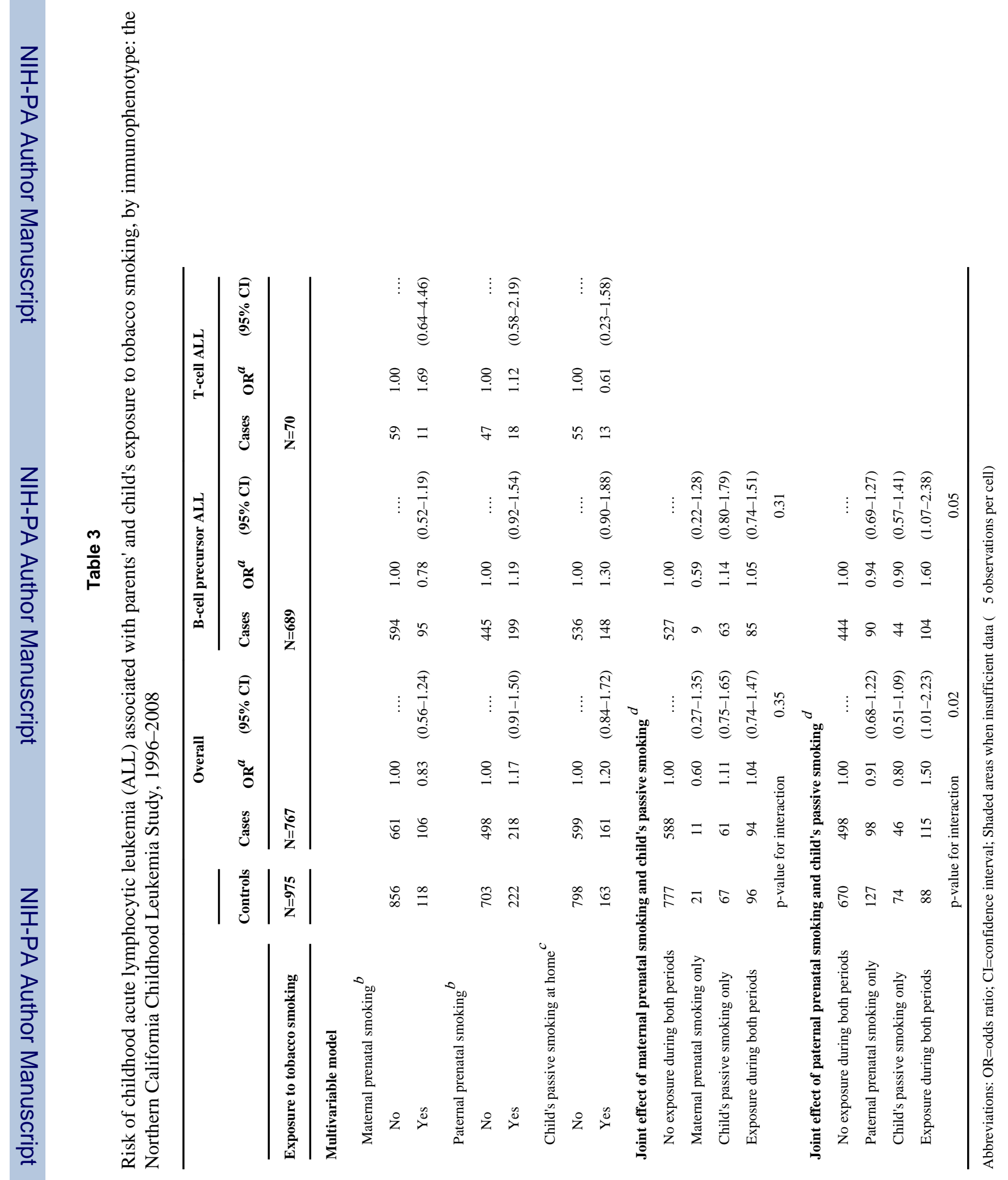




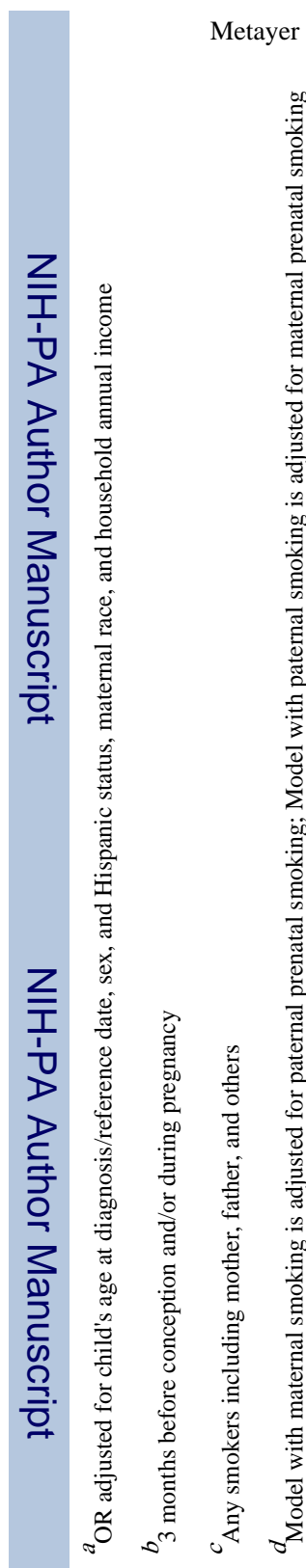

Page 16

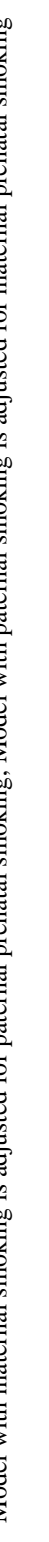




\section{Table 4}

Risk of childhood acute lymphocytic leukemia (ALL) overall and B-cell precursor ALL associated with father's passive smoking 3 months before conception among non-smoking parents: the Northern California Childhood Leukemia Study, 2000-2008 (Phase 2)

\begin{tabular}{|c|c|c|c|c|c|c|c|}
\hline \multirow[b]{3}{*}{ Sources of passive smoking } & \multirow{3}{*}{$\frac{\text { Controls, } \mathbf{N}}{392}$} & \multirow{2}{*}{\multicolumn{2}{|c|}{$\begin{array}{ll} & \text { Overall } \\
\text { Cases, } \mathbf{N} & \text { OR }^{a}\end{array}$}} & \multirow[b]{2}{*}{$95 \% \mathrm{CI}$} & \multicolumn{3}{|c|}{ B-cell precursor ALL } \\
\hline & & & & & Cases, $\mathbf{N}$ & $\mathrm{OR}^{a}$ & $95 \% \mathrm{CI}$ \\
\hline & & 300 & & & 268 & & \\
\hline \multicolumn{8}{|l|}{ Home } \\
\hline No & 379 & 293 & 1.00 & $\ldots$ & 261 & 1.00 & $\ldots$ \\
\hline Yes & 10 & 7 & 0.82 & $(0.30-2.22)$ & 7 & 0.92 & $(0.34-2.54)$ \\
\hline \multicolumn{8}{|l|}{ Work place(s) } \\
\hline No & 312 & 232 & 1.00 & $\ldots$ & 209 & 1.00 & $\ldots$ \\
\hline Yes & 68 & 59 & 1.08 & $(0.73-1.62)$ & 52 & 1.05 & $(0.69-1.59)$ \\
\hline \multicolumn{8}{|l|}{$\operatorname{Car}(s)$} \\
\hline No & 359 & 265 & 1.00 & $\ldots$ & 235 & 1.00 & $\ldots$ \\
\hline Yes & 23 & 30 & 1.50 & $(0.84-2.69)$ & 29 & 1.66 & $(0.92-3.00)$ \\
\hline \multicolumn{8}{|l|}{ Public area(s) } \\
\hline No & 301 & 224 & 1.00 & $\ldots$ & 200 & 1.00 & $\ldots$ \\
\hline Yes & 87 & 71 & 1.04 & $(0.72-1.51)$ & 63 & 1.04 & $(0.71-1.53)$ \\
\hline
\end{tabular}

Cancer Epidemiol Biomarkers Prev. Author manuscript; available in PMC 2014 September 01. 


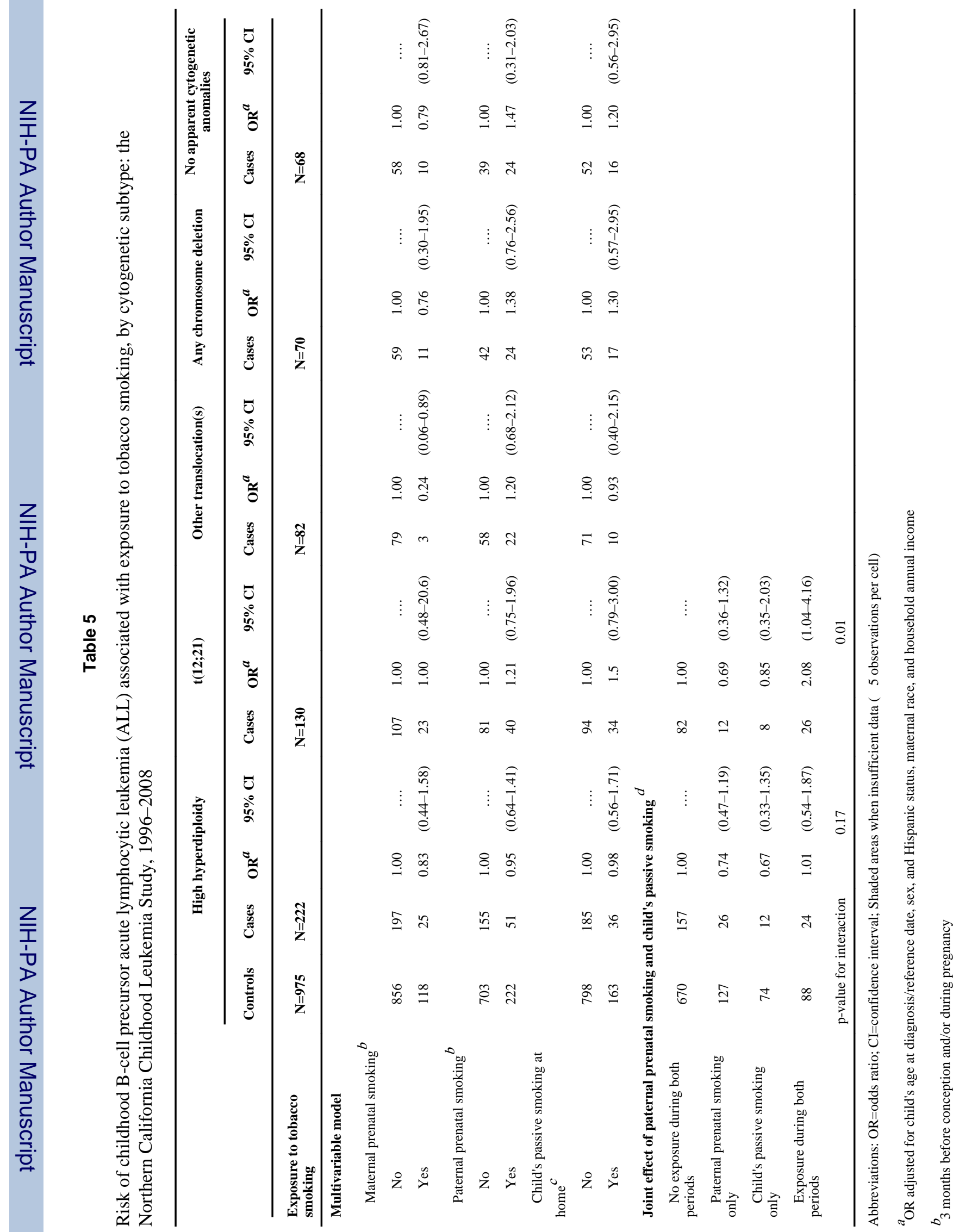

Cancer Epidemiol Biomarkers Prev. Author manuscript; available in PMC 2014 September 01. 


(1)

Cancer Epidemiol Biomarkers Prev. Author manuscript; available in PMC 2014 September 01. 


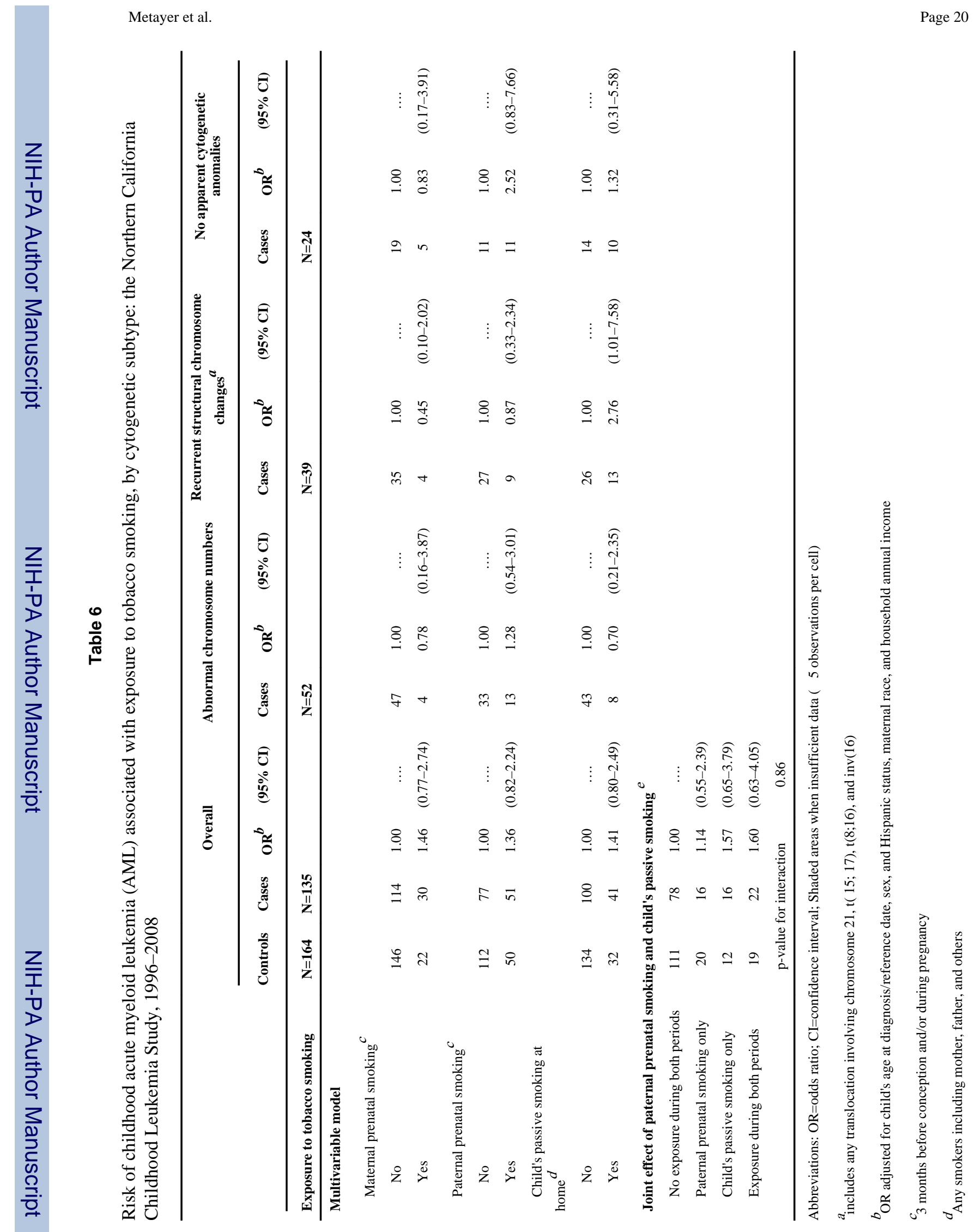

Cancer Epidemiol Biomarkers Prev. Author manuscript; available in PMC 2014 September 01. 
